\title{
Further Evidence for the Implication of LZTR1, a Gene Not Associated with the Ras-Mapk Pathway, in the Pathogenesis of Noonan Syndrome
}

Nehla Ghedira $^{1^{*}}$, Lilia Kraoua ${ }^{2}$, Arnaud Lagarde $^{3,4}$, Rim Ben Abdelaziz ${ }^{5}$, Sylviane Olschwang ${ }^{3,4}$, Jean Pierre Desvignes ${ }^{4}$, Sonia Abdelhak $^{6}$, Kamel Monastiri $^{1,7}$, Nicolas Levy 3,4 , Annachiara De Sandre-Giovannoli ${ }^{3,4}$ and Ridha Mrad ${ }^{2}$

${ }^{1}$ Research Unit 01/UR/08-14, University of Monastir, Monastir, Tunisia

${ }^{2}$ Department of Congenital and Hereditary Disorders, Charles Nicolle Hospital, Tunis, Tunisia

${ }^{3}$ Aix Marseille University, INSERM, GMGF UMR_S 910, Marseille, France

${ }^{4}$ Departement of Medical Genetics, Children Hospital La Timone, Marseille, France

${ }^{5}$ Department of Paediatrics, La Rabta Hospital, Tunis, Tunisia; Tunis El Manar University, Faculty of Medicine of Tunis, Tunisia

${ }^{6}$ Laboratory of Biomedical Genomics and Oncogenetics LR11IPT05, Institut Pasteur de Tunis, Tunis, Tunisia

${ }^{7}$ Department of Intensive Care and Neonatal Medicine, CHU Fattouma Bourguiba, Monastir, Tunisia

*Corresponding author: Nehla Ghedira, Faculty of Medicine, University of Monastir, Monastir, Tunisia, Tel: 0021623708351; E-mail: gnehla@yahoo.fr Received date: July 20, 2017; Accepted date: September 28, 2017; Published date: October 05, 2017

Copyright: (C) 2017 Ghedira N, et al. This is an open-access article distributed under the terms of the Creative Commons Attribution License, which permits unrestricted use, distribution and reproduction in any medium, provided the original author and source are credited.

\section{Abstract}

Background: Noonan Syndrome (NS) is a relatively common autosomal dominant condition, caused by germline mutations in different genes involved in the RAS MAP Kinase signaling pathway. Although clinically heterogeneous, characteristic findings include typical facial features, short stature, chest deformity and congenital heart diseases.

Methods: Here, we present the clinical and molecular characterization of a Tunisian patient with NS. A comprehensive mutations analysis of 29 genes belonging to the RAS pathway or encoding for interactors was performed, using targeted next generation sequencing.

Results: The results revealed a novel pathogenic substitution affecting the LZTR1, whose mutations have been described only in 5 cases of NS.

Conclusion: This report supports the implication of LZTR1 in Noonan syndrome. Next Generation Sequencing seems a suitable method for mutation detection in clinically and genetically heterogeneous syndromes such as NS.

Keywords: Noonan syndrome; RASopathy; Targeted NGS; RASMAPK pathway; LZTR1

\section{Introduction}

The RAS-MAPK pathway is essential in cell growth, differentiation, senescence and in regulating cell cycle [1-3]. Germline mutations of genes involved in the RAS/MAPK signaling pathway result in a spectrum of phenotypically overlapping syndromes named RASopathies or RAS/mitogen-activated protein kinase (MAPK) syndromes $[4,5]$. These disorders include neurofibromatosis type 1 (NF1, OMIM 162200), Legius syndrome (NFLS, OMIM 611431), Noonan syndrome (NS, OMIM 163950), Noonan syndrome with multiple lentigines (also called LEOPARD syndrome, LS, OMIM 151100), Costello syndrome (CS, OMIM 218040), cardiofaciocutaneous syndrome (CFCS, OMIM 115100), Noonan-like syndromes, hereditary gingival fibromatosis (HGF, OMIM 135300), and capillary malformation-arteriovenous malformation (CMAVM, OMIM 608354). The most frequent RASopathy remains NS with a prevalence estimated to be between 1:1000 to 1:2500 live births [6,7].

Noonan syndrome (NS, OMIM 163950) is an autosomal dominant multisystem disorder characterized by a wide phenotypic spectrum including distinctive facial dysmorphism, postnatal growth retardation, short stature, ectodermal and skeletal defects, congenital heart anomalies, renal anomalies, lymphatic malformations, bleeding difficulties and variable cognitive deficits [8-10].

NS was already associated with PTPN11, SOS1, KRAS, NRAS, RAF1, BRAF,MAP2K1/2 SHOC2, CBL and RIT1 gene mutations $[2,7,11]$. Recently, novel gene variants affecting $R R A S, R A S A 2$, $A 2 M L 1, S O S 2$ and $L Z T R 1$ have been shown to be associated with NS and RASopathies [12].

Here we report a new case of a Tunisian patient with Noonan syndrome caused by $L Z T R 1$ mutation.

\section{Case Presentation}

The patient, a 6-year-old Tunisian boy, was the second child of healthy unrelated parents aged 26 (mother) and 41 years (father). The family history was unremarkable. His two brothers were healthy. Pregnancy and delivery were normal, and the boy was born at term. His birth weight was $3300 \mathrm{~g}$, his length $49 \mathrm{~cm}$ and his head circumference $33 \mathrm{~cm}$. He sat alone at $2 \frac{1}{2}$ years, walked at 4 years 10 months and had speech delay.

The patient was referred for consultation because of psychomotor retardation and facial dysmorphism. On examination at the age of 4 years, his weight was $13 \mathrm{~kg}(-3 \mathrm{SD})$, his height $89 \mathrm{~cm}(-4,3 \mathrm{SD})$ and his head circumference $46 \mathrm{~cm}$ (-2,6 SDS, Standard Deviation Score). $\mathrm{He}$ 
Citation: Ghedira N, Kraoua L, Lagarde A, Abdelaziz RB, Olschwang S, et al. (2017) Further Evidence for the Implication of LZTR1, a Gene Not Associated with the Ras-Mapk Pathway, in the Pathogenesis of Noonan Syndrome. Biol Med (Aligarh) 9: 414. doi: 10.4172/0974-8369.1000414

Page 2 of 4

had facial dysmorphism suggestive of Noonan syndrome including frontal bossing, downslanting palpebral fissures, thick lips, anteverted nose, low-set and posteriorly rotated ears and short webbed neck withlow posterior hairline, dental caries, thoracic deformation with pectus excavatum, hypospadias, cryptorchidism, fingers' hyperlaxity, valgus flat feet, loose excess skin on hands and heart murmur (Figure 1).
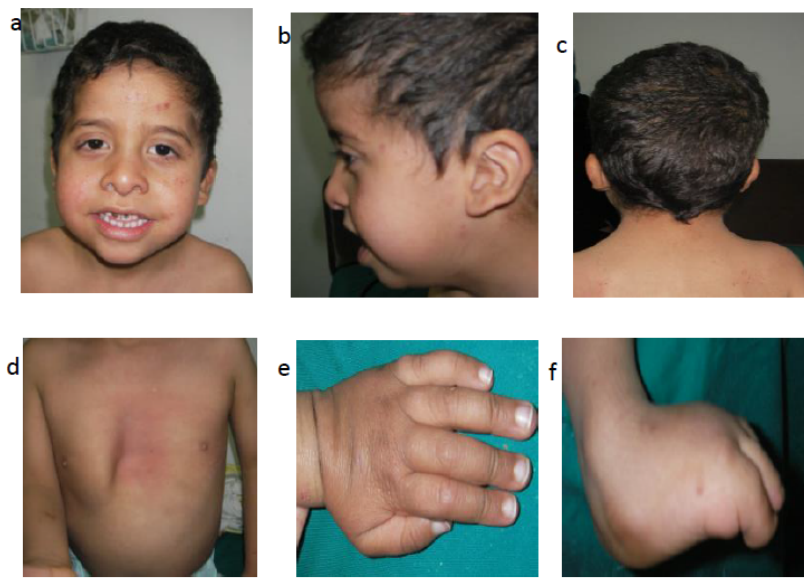

Figure 1: Photographs of the patient at 4 years. (a) downslanting palpebral fissures, thick lips, anteverted nose, dental carries; (b) low-set and posteriorly rotated ears; (c) short webbed neck with low hairline; (d) thoracic deformation with pectus excavatum; $€$ loose excess skin on hands and (f) valgus flat foot.

The cardiac exam showed hypertrophic cardiomyopathy, ostium secundum atrial septal defect and mitral anomaly.

Ophthalmologic examination, auditory and visual evoked potentials and brain magnetic resonance imaging were normal.

Laboratory analyses showed normal levels of TSH and FT4, IGF1 and blood phenylalanine. Urinary glycosaminoglycan screening was negative. Blood count revealed normochromic and normocytic anemia. Chromosomal analysis was normal: $46, \mathrm{XY}$.

\section{Methods}

Genomic DNA of the patient was manually extracted from peripheral blood collected in EDTA tubes according to standard salting out methods and purified by QIAmp DNA microkit (Qiagen).

Genomic DNA of asymptomatic patient's relatives (mother, paternal uncle and brother) was extracted from buccal cells using QIAmp DNA blood mini Kit (Qiagen-Cat.No.51 104).

The Ion Torrent PGM system was used to sequence exons and splicing sites of 29 genes of the RAS MAPK signaling pathway involved in Noonan syndrome and other rasopathies, i.e.,: the commonly mutated PTPN11, SOS1, RAF1, KRAS, BRAF, NRAS, HRAS, $M A P 2 K 1, M A P 2 K 2$, SHOC2, CBL, SPRED1 genes and less common ones such as LZTR1 (more details about the complete list of genes are provided under request). The library kit was made with Agilent Haloplex technologies. The sequence analysis software was VarAFT (http://varaft.eu). Prediction of functional effects of nsSNPs was done with UMD predictor, MutationTaster and PolyPhen. Variants of interest were verified using the Integrative Genomics Viewer and validated by bidirectional Sanger Sequencing.

\section{Results}

A total of 163 variants were detected across the 29 genes analyzed. Filtering these results using in silico software predictors of mutation's impact revealed only one heterozygous variant as potentially pathogenic: a heterozygous missense mutation in exon 4 of the LZTR1 gene predicted to lead to a missense amino acid change (NM_006767:c.347C>T, p.Ala116Val). This alteration was validated using Sanger sequencing in proband's and available relatives, showing that it appeared de novo (Figure 2).

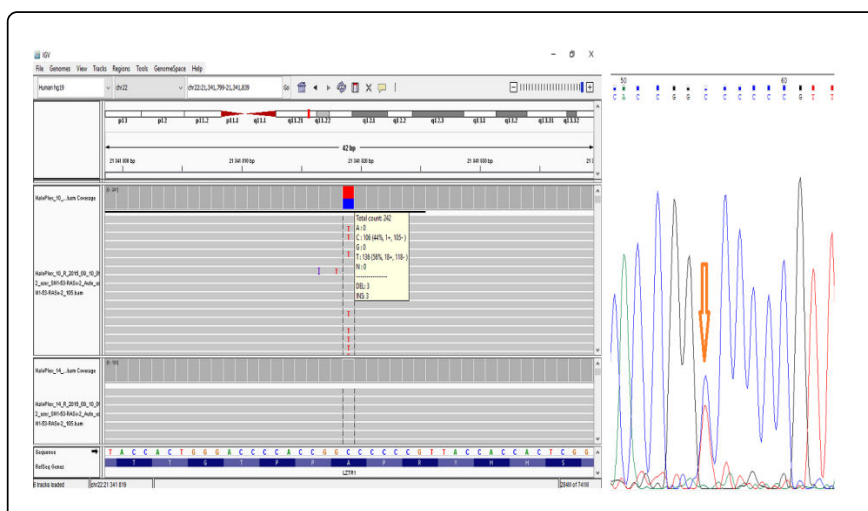

Figure 2: Sequencing results. IGV browser visualization of the targeted NGS sequencing results showing the heterozygous c. $347 \mathrm{C}>\mathrm{T}$ substitution in the LZTR1 gene in the patient and the Sanger Sequencing validation.

\section{Discussion}

In this study, we report a case of NS with typical clinical findings, harboring a mutation in LZTR1 (Leucine-Zipper-like Transcriptional Regulator-1), a gene rarely associated with NS.

LZTR1, located at 22q11.21, encodes a protein member of the BTBKelchsuperfamily implicated in several fundamental cell processes. The implication of LZTR1 in human disease was first reported with the DiGeorge Syndrome, as it was deleted in the majority of DiGeorge Syndrome patients [13]. More recently, somatic mutations with loss of heterozygosity in LZTR1 and germline loss-of-function variants in LZTR1 were respectively associated with glioblastoma multiforme [14] and schwannomatosis $[15,16]$.

Germline LZTR1 variants in Noonan syndrome patients were first reported by Chen et al. in [17]. The authors performed Next Generation Sequencing in a cohort of 27 NS patients without a known NS gene mutation. Two of these patients had LZTR1 variants (p.R237Q and p.A249P) which were not considered as responsible for the NS phenotype, since the authors considered LZTR1 as a gene already associated with DiGeorge syndrome. In 2015, Yamamoto et al. identified rare variants of $L Z T R 1$ using whole-exome sequencing in 6/50 Brazilian probands (p.G248R, p. R284C, p.H287Y, p.Y119C, p.I647Vand p.F447L) and one Polish family ( p.S247N ) with NS and lacking mutation in the known NS genes [18]. Two of these variants were considered nonpathogenic because of their presence in unaffected relatives (p.F447L) or the weak of in silico pathogenicity prediction 
Citation: Ghedira N, Kraoua L, Lagarde A, Abdelaziz RB, Olschwang S, et al. (2017) Further Evidence for the Implication of LZTR1, a Gene Not Associated with the Ras-Mapk Pathway, in the Pathogenesis of Noonan Syndrome. Biol Med (Aligarh) 9: 414. doi: 10.4172/0974-8369.1000414

Page 3 of 4

(p.I647V). The remaining five variants, p.G248R, p. R284C, p.H287Y, p.Y119C and p.S247N, were predicted to cause NS as they segregated with the NS phenotype or were de novo events and predicted to be deleterious by in silico analysis. Moreover, the LZTR1 variants identified in Brazilian patients were found in only $1 / 107$ control cohort supporting their implication in NS. All the reported LZTR1 variants are localized in highly conserved kelch (KT) domain and are predicted to disrupt protein function. Kelch domain shape may also be responsible for binding to other proteins $[19,20]$. The missense heterozygous variant found in LZTR1 in our patient is localized in KT1 domain. In silico analysis predicted pathogenicity. Analysis of a control database of WES in 50 Tunisian patients affected by other disorders showed no LZTR1 variant. The mechanism by which mutations in LZTR1 causes NS is still unknown. Yamamoto et al. [18] suggested that missense heterozygous variants in LZTR1 may cause dysregulation of the RAS/MAPK pathway by increasing ERK signaling through a loss of tumor suppressor function.

The clinical findings of NS patients with LZTR1 variants were similar to PTPN11 positive individuals with the exception of short stature which was not frequent in the Brazilian cohort [19]. Our patient, contrary to what has been reported, had a short stature at $-4,3$ SD (Standard Deviation).

Table 1, updated from Yamamoto et al. [18], summarizes the clinical features seen in reported cases of NS patients with LZTR1 variants and highlights similarities between clinical findings seen in the 5 previously reported cases and in our case.

\begin{tabular}{|c|c|c|c|c|c|c|}
\hline & Brazil F3 & Brazil F4 & Brazil F5 & Brazil F6 & Poland F1 & Tunisian (this report) \\
\hline & Proband & Proband & Proband & Proband & Proband & Proband \\
\hline \multicolumn{7}{|l|}{ Clinical findings } \\
\hline Sex & Female & Female & Male & Female & Male & Male \\
\hline Age & 11 years 5 months & 14 years & $\begin{array}{l}16 \text { years } 1 \\
\text { month }\end{array}$ & 30 years & 18 years & 4 years 9 months \\
\hline \multicolumn{7}{|l|}{ Perinatal data } \\
\hline Gestational age & Term & Term & 35 weeks & Term & Term & Term \\
\hline BW, $g$ & 2270 & 2750 & 2130 & 3930 & 4000 & \\
\hline Length, $\mathrm{cm}$ & 45 & & 47 & 52 & 53 & \\
\hline Typical facial features & + & + & + & + & + & + \\
\hline Current height & $131.5 \mathrm{~cm}$ & $146 \mathrm{~cm}$ & 172.6 & 146 & 183 & 93 \\
\hline Short/webbed neck & + & - & - & - & + & + \\
\hline Pectus deformity & + & + & - & - & + & + \\
\hline Cardiac abnormality & PVS/ASD & PVS & PVS/ASD & LVH & $\mathrm{MVI}$ & $\mathrm{ClA} / \mathrm{HCM}$ \\
\hline Cryptorchidism & NA & NA & + & NA & - & + \\
\hline Renal abnormality & - & - & - & - & - & - \\
\hline Abnormal hemostatis & - & + & + & - & - & - \\
\hline Factor XI deficiency & & - & - & - & - & - \\
\hline $\begin{array}{l}\text { Ophthalmological } \\
\text { abnormality }\end{array}$ & + & & + & - & - & - \\
\hline Ectodermal findings & - & - & - & - & + & + \\
\hline Curly hair & - & - & - & - & - & - \\
\hline Sparse eyebrows & - & - & - & - & - & + \\
\hline Hyperkeratosis pilaris & - & - & - & - & - & - \\
\hline Ulerythema ophriogenes & - & - & - & - & - & + \\
\hline Tumours & - & - & - & - & + & - \\
\hline Developmental delay & - & - & + & - & + & + \\
\hline Learning ability & - & - & + & - & + & \\
\hline
\end{tabular}


Citation: Ghedira N, Kraoua L, Lagarde A, Abdelaziz RB, Olschwang S, et al. (2017) Further Evidence for the Implication of LZTR1, a Gene Not Associated with the Ras-Mapk Pathway, in the Pathogenesis of Noonan Syndrome. Biol Med (Aligarh) 9: 414. doi: $10.4172 / 0974-8369.1000414$

Page 4 of 4

\begin{tabular}{|c|c|c|c|c|c|c|}
\hline Other findings & Lacrimal duct & & & Lymphedem & se veins & \\
\hline Mutation (NM_006767,3) & $\begin{array}{l}\text { c. } 742 G>A ; \\
\text { p.G248R }\end{array}$ & $\begin{array}{l}\text { c. } 850 C>T ; \\
\text { p..R284C }\end{array}$ & $\begin{array}{l}\text { c.859C>T; } \\
\text { p.H287Y }\end{array}$ & $\begin{array}{l}\text { c.356A>G; } \\
\text { p.Y119C }\end{array}$ & c. $740 \mathrm{C}>\mathrm{A} ;$ p.5247N & c.347C>T;p.A116V \\
\hline
\end{tabular}

ASD: Atrial Septal Defect; BW: Birth Weight; WHO: World Health Organisation; HCM: Hypertrophic Cardiomyopathy; LVH: Left Ventricular Hypertrophy; MVI: Mitral Valve Insufficiency; NA: Not Applicable; NS: Noonan Syndrome; PVS: Pulmonary Valve Stenosis; SDS: SD Score

Table 1: Summary of clinical details of Noonan syndrome patients with LZTR1 variants.

Our case further supports the implication of LZTR1 in the pathogenesis of NS. Nevertheless, functional studies are required to unravel the precise implication of LZTR1 variant of p.Ala116Val in Noonan syndrome.

\section{Conclusion}

The identification of causative mutations that underlie genetically heterogeneous syndromes such as Noonan Syndrome has been greatly facilitated by the emergence of high throughput sequencing. In this context, Targeted NGS methods can be used as a cost effective first line genetic test for confirmation of NS cases. Thus, an early and accurate genetic diagnosis and suitable management of patients will be possible. The case we report supports the involvement of LZTR1 in the pathogenesis of typical Noonan syndrome.

\section{Acknowledgments}

We thank the patient and his family for participating in this research. We would like to thank also both the personnel of the Department of Intensive Care and Neonatal Medicine, CHU Fattouma Bourguiba, Monastir, Tunisia and all members of the team of the INSERM unit UMR_S910, GMGF, Aix Marseille University, Marseille, France (Karim Harhouri, Cathy Bartoli, Guy Longepied, Françoise Merono...). This study was partially funded by the University Foundation $\mathrm{A}^{\star}$ MIDEX.

\section{Competing Interests}

The authors declare that they have no competing interests.

\section{Author Details}

Unit research 01/UR/08-14 Faculty of Medecine of Monastir, University of Monastir, Monastir 5000, Tunisia.

\section{References}

1. Aoki Y, Niihori T, Narumi Y, Kure S, Matsubara Y (2008) The RAS/ MAPK syndromes: Novel roles of the RAS pathway in human genetic disorders. Hum Mutat 29: 992-1006.

2. Jorge AA, Malaquias AC, Arnhold IJ, Mendonca BB (2009) Noonan syndrome and related disorders: A review of clinical features and mutations in genes of the RAS/MAPK pathway. Horm Res 71: 185-193.

3. Tidyman WE, Rauen KA (2009) The RASopathies: developmental syndromes of Ras/MAPK pathway dysregulation. Curr Opin Genet Dev 19: 230-236.
4. Rauen KA (2013) The RASopathies. Annu Rev Genomics Hum Genet 14: 355-69.

5. Hernandez-Martin A, Torrelo A (2011) Rasopathies: developmental disorders that predispose to cancer and skin manifestations. Actas Dermosifiliogr 102: 402-416.

6. Tartaglia M, Zampino G, Gelb BD (2010) Noonan syndrome: clinical aspects and molecular pathogenesis. Mol Syndromol 1: 2-26.

7. Turner AM (2011) Noonan syndrome. J Paediatr Child Health 47: 1-7.

8. Gelb BD, Tartaglia M (2006) Noonan syndrome and related disorders: dysregulated RAS-mitogen activated protein kinase signal transduction. Hum Mol Genet 15: R220-226.

9. Allanson JE, Bohring A, Dörr HG, Dufke A, Gillessen-Kaesbach G, et al. (2010) The face of Noonan syndrome: Does phenotype predict genotype. Am J Med Genet A 152A: 1960-1966.

10. Romano AA, Allanson JE, Dahlgren J, Gelb BD, Hall B, et al. (2010) Noonan syndrome: Clinical features, diagnosis, and management guidelines. Pediatrics 126: 746-759.

11. Lee BH, Kim JM, Jin HY, Kim GH, Choi JH, et al. (2011) Spectrum of mutations in Noonan syndrome and their correlation with phenotypes. J Pediatr 159: 1029-1035.

12. Aoki Y, Niihori T, Inoue S, Matsubara Y (2016) Recent advances in RASopathies. J Hum Genet 61: 33-9.

13. Kurahashi H, Akagi K, Inazawa J, Ohta T, Niikawa N, et al. (1995) Isolation and characterization of a novel gene deleted in DiGeorge syndrome. Hum Mol Genet 4: 541-549.

14. Frattini V, Trifonov V, Minhow Chan J, Castano A, Lia M, et al. (2013) The integrated landscape of driver genomic alterations in glioblastoma. Nat Gene 45: 1141-1149.

15. Paganini I, Chang VY, Capone GL, Vitte J, Benelli M, et al. (2015) Expanding the mutational spectrum of LZTR1 in schwannomatosis. Eur J Hum Genet 23: 963-968.

16. Smith MJ, Isidor B, Beetz C, Williams SG, Bhaskar SS, et al. (2015) Mutations in LZTR1 add to the complex heterogeneity of schwannomatosis. Neurology 84: 141-147.

17. Chen P, Yin J, Yu HW, Yuan T, Fernandez M, et al. (2014) Next-generation sequencing identifies rare variants associated with Noonan syndrome. Proc Natl Acad Sci USA 111: 11473-11478.

18. Yamamoto GL, Aguena M, Gos M, Hung C, Pilch J, et al. (2015) Rare variants in SOS2 and LZTR1 are associated with Noonan syndrome. J Med Genet 52: 413-421.

19. Dhanoa BS, Cogliati T, Satish AG, Bruford EA, Friedman JS (2013) Update on the Kelch-like (KLHL) gene family. Hum Genomics 7: 13.

20. Nacak TG, Leptien K, Fellner D, Augustin HG, Kroll J (2006) The BTBkelch protein LZTR-1 is a novel Golgi protein that is degraded upon induction of apoptosis. J Biol Chem 281: 5065-5071. 